\title{
21st International Symposium on Shiftwork and Working Time: The 24/7 Society - From chronobiology to practical life
}

\author{
Frida Marina Fischer ${ }^{1}$, Sampsa Puttonen ${ }^{2}$, and Debra J. Skene ${ }^{3}$ \\ ${ }^{7}$ Department of Environmental Health, School of Public Health, University of São Paulo, São Paulo, Brazil, ${ }^{2}$ Finnish Institute \\ of Occupational Health, Center of Expertise for Development of Work and Organizations, Helsinki, Finland, and \\ ${ }^{3}$ Department of Chronobiology, Faculty of Health and Medical Sciences, University of Surrey, Guildford, UK
}

\section{INTRODUCTION}

Some significant changes have taken place in the global economy in recent decades impacting dramatically on the organization of work. The so-called "productive restructuring" has come with a growth of precarious work, work intensification, reduction in employment rates, flexibility of working times and off-hours not necessarily favorable to the wellbeing of workers. The global economic adjustments have also resulted in the weakening of labor unions, increase of informal jobs and structural unemployment in many countries (Kawachi, 2008; Quinlan et al., 2001; Santana, 2012). In addition, we face increasing age of the working population and the permanent presence of inequality at work and in health (Costa \& Di Milia, 2008). Even in the select group of the so-called "developed industrial countries" we can often observe many cases of bad working conditions that contribute to the early development of work-related illnesses, both physical and mental, affecting not only the workers but also their families and social lives. ${ }^{1}$

In 2007, The International Labor Organization published the document "Working time around the world: Trends in working hours, laws and policies in a global comparative perspective" (Lee et al., 2007). The authors noted the large variation in the length of the weekly working hours and resting times within work sectors and countries. According to these authors... "Adjustments of the duration of decent work must meet five criteria, all interconnected which is why the work arrangements should: preserve health and safety, be family-friendly, promote gender equality, enhance productivity, facilitate workers' choice of their working hours". For example, the rapid economic growth and productivity gains have contributed to rising wages in some Asian developing countries, but the benefits of growth have not translated into shorter work hours" (ILO, 2005). A recent report from ILO (2014) pointed out that "employment and social challenges remain acute in most emerging and developing countries. More than half of the developing world's workers (i.e., nearly 1.5 billion people) are in vulnerable employment".

Night and shiftwork, long and irregular working hours are usually associated with other environmental and organizational health risk factors (Caruso, 2014; Caruso et al, 2006; Harma \& Kecklund, 2010).

In recent years, a significant number of publications have reported negative outcomes related with shiftwork/night work and/or length of working time associated with metabolic diseases, as well as cardiovascular diseases. However, many issues, including the increased risk of developing malignant tumors during night work are still controversial (Ijaz et al., 2013; Haus \& Smolensky, 2013). Currently a number of cohort studies utilizing more comprehensive measures aim to look more closely at this outcome. This new evidence is needed to develop better protection of workers in addition to the usually recommended actions.

Shiftworkers and night workers can be at a severe disadvantage compared with day workers. In many cases, the former have to cope with multiple stressors associated with adverse work organization; they may also be exposed to other stressors- such as chemical contaminants, strenuous work activities combined with poor living conditions. As researchers we must look at the combined effects of several stressors in order to better understand and put into practice safer threshold exposure limits and prevent aggravation of work-related

Correspondence: Frida Marina Fischer, Department of Environmental Health, School of Public Health, University of São Paulo, São Paulo, Brazil. E-mail: fischer.frida@gmail.com

${ }^{1}$ Some of the ideas expressed in this Introduction were delivered by Frida M. Fischer during previous shiftwork symposia (2011;2013) 
diseases and higher risks of work injuries. However, the literature still lacks such advanced studies. Here we would like to cite Giovanni Costa from 2010 who stated: “. . it is necessary to apply a systemic approach, dealing with the different domains which in turn can affect the outcomes and address the interventions at their best, involving physiopathology, psychology, sociology, ergonomics, economics, politics, and ethics" (Costa, 2010). Moreno \& Lowden (2014) confirmed this view when arguing in a recent editorial published by the Scandinavian Journal of Work Environment Health on workplace interventions to promote long-term health among shiftworkers. The authors wrote that "a broad variety of health promoting strategies are required to achieve long-term positive effects".

For more than 40 years, The International Symposium on Shiftwork and Working Time meetings (formerly called the International Symposia of Shift and Night work), have been the major international scientific forum to present the results of studies in this area. The recent 21st International Symposium on Shiftwork and Working Time entitled "The 24/7 society: from chronobiology to practical life", was jointly organized by the Working Time Society, the International Commission on Occupational Health (ICOH) Subcommittee Shiftwork and Working Time, University of São Paulo and Oswaldo Cruz Foundation. The meeting was held on 4-8 November 2013, at Costa do Sauípe, Bahia State, Brazil and during the symposium findings on a large variety of issues ranging from basic chronobiology to practical solutions at work were presented, in total 156 studies (Moreno et al., 2013). The workshops and oral sessions focused on: new trends in working hours; socially sustainable working hours; sleep disorders, health, safety and performance; working hours and sleep; circadian stress, shiftwork and influence of light; genes, rhythms and light; cancer and shiftwork; shiftwork and the individual; physical and mental health; nutrition, metabolism and physical activity. Methods and models useful for interventions on shiftwork were presented in the workshop session "Experiences with resistance of workers towards changes and how to address it"; and a special session addressing issues of methods and models on alertness, sleep and fatigue at work. A detailed program is presented in the Proceedings of the Symposium published in Sleep Science (Moreno et al., 2013).

Since 2004 the Journal Chronobiology International has released a Special Issue after each of the International Symposia on Shiftwork and Working Time. This tradition continues here with this Special Issue (Chronobiology International 2014) that includes 17 referred manuscripts covering important themes regarding working time. The selected articles are grouped under three main titles: Health and working time; Sleep, fatigue, performance and alertness; and Lifestyle and work-related stress.

\section{Health and working time}

Health and working time have been a matter of concern for a long time. Studying the broad and multifaceted effects of working time on health started decades ago with studies focusing on traditional shift and night work. More recently the study questions have broadened to other areas such as overtime, long working hours and working from home (Caruso, 2006).

This Special Issue includes nine reports related to health and working time. The first article authored by Arlinghaus \& Nachreiner (2014) addresses a more recent concern of possible health effects of overtime working from home. They used two large databases of European Union workers - the European Working Conditions Survey held in 2005 and 2010. The results showed an increased risk reporting at least one health problem when the employees were contacted by employers at home or worked in their free time. The authors recommended work activities be restricted to within regular or contractually work hours allowing workers to achieve adequate recovery during their time off.

Overtime was the main studied variable of the work by Imai et al. (2014). The hypothesis of this study was whether hypertension is associated with long working hours. Data from more than Japanese 50,000 workers from 4 companies were evaluated. The results showing an inverse association between overtime work and prevalence of hypertension contradicted two former studies (Artazcoz et al., 2009; Yang et al., 2006), but confirmed others (Wada et al., 2006; Nakanishi et al., 2001). Despite the large database, the authors highlighted the cross-sectional design as the main study limitation that left the possibility open of residual effects of potential confounders and differences in assessments of overtime and blood pressure evaluation among the companies.

Breast cancer and shiftwork has been a rather controversial theme, raising a debate as to whether exposure to night work leading to circadian disruption and exposure to light at night leading to melatonin suppression are associated with increased risk of cancer (Haus \& Smolensky, 2013; Ijaz et al., 2013; Viswanathan \& Schernhammer, 2009; WHO/IARC, 2007). In this issue, Dumont \& Paquet (2014) investigated the degree of melatonin suppression in a simulated night work experiment. Their findings confirm that melatonin production progressively decreased during consecutive days of night work, both during the night and over the $24 \mathrm{~h}$. According to previous experimental observations the decrease in melatonin production may reflect some circadian disruption.

Rea \& Figueiro (2014) presented a method to quantify circadian disruption in humans and animal models, so-called "phasor analysis". This analysis can be used in laboratory and field studies. The authors noted the importance of establishing a bridge between ecological measurements of circadian entrainment in humans and studies of circadian disruption in animal models. 
Genetic variants and environmental factors are another avenue for research linking shiftwork and breast cancer. The GENICA study conducted in the greater region of Bonn, Germany by Rabstein et al. (2014), looked at associations between polymorphisms in circadian genes (CLOCK, NPAS2, ARNTL, PER2 and CRY2), genes of melatonin biosynthesis and signaling (AANAT and MTNR1B), breast cancer and shiftwork. Their results support the putative role of the circadian gene, CLOCK, in the development of breast cancer in shiftworkers. Other relevant genes associated with the outcome were MTNR1B, NPAS2 and ARNTL. The authors propose multivariable models to study polymorphisms that may influence chronotype or light sensitivity.

According to the literature, shiftwork is associated with a high prevalence of a number of noncommunicable diseases, including obesity, metabolic syndrome and diabetes (Szosland, 2010). A number of studies aiming to better understand the complex physiological mechanisms involved in this association have been conducted. Studies presented in this Special Issue provide new evidence of possible underlying mechanisms.

Balieiro et al. (2014) compared anthropometry and food intake patterns in bus drivers working during the day and night and found a high prevalence of inappropriate feeding practices, excess weight and abdominal obesity among drivers of both groups, but most of the observed problems were more associated with drivers on night work than day work. These results suggest that a night work schedule can lead to nutritional and metabolic problems that are associated with high morbidity and mortality, such as obesity and its associated comorbidities.

The study conducted by Mota et al. (2014) evaluated the relationship between sleep quality, adipokine levels and nutritional patterns in Brazilian resident physicians. The results of this study showed that resident physicians with poor sleep quality have lower levels of ghrelin, and that women experiencing excessive daytime sleepiness have lower levels of leptin. These observations indicate that the sleep patterns and long working hours of resident physicians are negatively associated with biological markers related to central food control and lipid profiles, as well as with eating healthy foods and cholesterol levels. These results suggest that the workload of resident shiftworkers can affect the intake of healthy foods and adversely impact the lipid profile that may in turn predispose these shiftworkers to become overweight and develop metabolic disorders. Therefore, it is reasonable to assume that in resident physicians a pattern of impaired sleep can lead to nutritional and metabolic changes that are associated with food intake of low quality.

Kantermann et al. (2014) conducted an exploratory pilot study to investigate the risk of metabolic abnormalities in steel workers employed in different shiftwork rotations (fast clockwise rotation, slow counterclockwise rotation, day workers). They hypothesized that the social jetlag arising from different shift schedules could significantly impact metabolic risk blood markers. As expected, shiftworkers had significantly more social jetlag than day workers. Fasting glucose and HOMA index were lowest in fast clockwise rotation shiftworkers, possibly pointing towards a healthier metabolic status in this group. Future studies should control the impact of food intake on these measures in the shiftwork environment. The findings from this pilot study support future studies of shift-workers in different shift rotations to further elucidate the interaction between work times, shift schedules, sleep and lifestyle.

In a systematic review Knutsson \& Kempe (2014) studied the potential association between shiftwork and type 2 diabetes. They identified only seven epidemiological cohort studies on the association between shiftwork and diabetes and all the studies demonstrated increased risk of diabetes in shiftworkers, but in some of these studies the results were not statistically significant. Due to the low number of studies the evidence was graded as moderate. The findings indicate that our current knowledge about work schedules and diabetes is limited, probably one reason why national guidelines on diabetes do not include advice about how to manage problems related to diabetes and shiftwork.

\section{Sleep, fatigue, performance and alertness}

Sleep loss leads to fatigue, decreased performance and alertness, and consequently an increased accident risk.

Kosmadopoulos et al. (2014) performed a study to establish whether splitting the sleep-wake cycle has an effect on neurobehavioral performance or individuals' predictions of their performance, and to determine the relative circadian and homeostatic contributions of any such effects. The authors designed forced desynchrony (FD) protocols where twenty-nine male participants lived in a time isolation laboratory for $13 \mathrm{~d}$, assigned to one of two 28-h FD. The results suggest that, overall, splitting the sleep-wake schedule is not detrimental to neurobehavioral performance. Splitting sleep opportunities also did not appear to affect total sleep time. However, those participants in the split schedule obtained a greater amount of slow wave sleep. The longer sleep episodes in the standard schedule coincided with predictions of consistently better performance than the split schedule, despite only facilitating better performance for a few hours after waking. Despite this, and provided sleep opportunities are properly utilized, these findings suggest that shorter work-rest shift cycles (e.g. $6 \mathrm{~h}$ on/6h off) may be satisfactorily implemented in place of longer work-rest shift cycles (e.g. $12 \mathrm{~h}$ on/12 h off) to sustain performance at all times of the day.

In the same context, Jackson et al. (2014) conducted a study with 53 healthy male volunteers to compare a sleep split schedule, where the sleep opportunities were 
split evenly into two sleep periods, with two conditions in which sleep was consolidated into a single period (either daytime consolidated sleep and or nighttime consolidated sleep), to determine the effects of the sleep patterns on sleep, performance and subjective state. Overall, participants in the nighttime and split sleep conditions obtained significantly more total sleep time than participants in the daytime sleep condition. While there was no clear effect of sleep schedule on performance measures, participants in the daytime sleep condition reported higher levels of sleepiness both within the work shift and across the simulated working week compared to the other two conditions, with no difference between the split and nighttime sleep conditions. Results of the present laboratory study suggest that split sleep schedules may be a good alternative to a consolidated daytime sleep in industries that allow for this kind of flexibility in their scheduling. On the other hand, further research in real-world situations is warranted to fully assess the efficacy of alternative split sleep schedules for improving safety and productivity.

The pursuit of excellence in performance already established in many areas of the world of work has also been applied in the field of sports (Barnett, 2006; Malcata \& Hopkins, 2014). It is feasible to assume that the effects of training sessions on sleep and fatigue among athletes are similar to those observed in real-life workers. The amount of sleep needed to reach or maintain high levels of performance has not yet been well-studied among elite athletes. Sargent et al. (2014) conducted a study with elite athletes to assess the impact of the training sessions on their sleep and fatigue. Differences in athletes' sleep behavior on training and rest days were observed; and a significant inverse effect of sleep duration on pre-training fatigue levels was noted. Not surprisingly findings from this study suggest that the amount of sleep of elite athletes is mediated by their training schedule. These results suggest that coachers need to be better informed about sleep-wake behavior in order to design adequate training schedules.

Other important aspect related to fatigue, decreased performance and alertness is the shift starting time. Lombardi et al. (2014) evaluated the impact of shift starting time on sleep duration and sleep quality, and the reported alertness/sleepiness of adults at the time of their injury in a multi-city epidemiological field study among hospitalized adults with severe work-related hand injury in China. The results suggest that sleep duration is shortest among injured adults starting shifts late at night and early in the morning. However, with more than $8.5 \mathrm{~h}$ of sleep on average work days, the Chinese workers slept much longer than typical US day workers.

\section{Lifestyle and work-related stress}

Recommendations for better designing of work schedules have long been suggested (Knauth, 1998; Knauth \&
Hornberger, 2003). One of the recommendations is to implement fast rotating shift schedules with enough time to rest in-between shifts. To establish shift-related differences in wellbeing and stress among nurses Costa et al. (2014) compared the effects of $2-3 \times 8 \mathrm{~h}$ shift rotas with backward rotation and quick return, to a $2 \times 12 \mathrm{~h}$ shift schedule with forward rotation. Sleep-wake timing, cortisol, reported sleep quality and sleepiness were evaluated in a subset of participants. Nurses working on a $2 \times 12 \mathrm{~h}$ rota showed reduced sleep disturbances, better recovery and more satisfying leisure time. However, the authors cautioned that the longer $12 \mathrm{~h}$ shifts may induce higher fatigue, and that interaction of the work context and social organization with shift schedules needs to be considered.

Another study of healthcare professionals aiming to investigate the association of shiftwork, job strain and heart rate variability was conducted by Karhula et al. (2014). Former studies in this field have not been conclusive. The participants of the present study were recruited from The Finnish Public Sector Study. Female health care professionals working in three shiftwork schedules self-reported their job strain using the Karasek's JCQ questionnaire. A subset of this large sample was invited to participate in a field study. Actigraphy and $24 \mathrm{~h}$ heart rate variability (HRV) measurements were conducted. No significant differences in HRV were detected before and during $30 \mathrm{~min}$ of sleep in the low and high job strain groups. These results suggest that exposures to stressful work environments are not necessarily associated with differences in HRV parameters.

Psychosocial factors at work include a number of variables, such as work demands, work pace, work control, social support that can affect workers' health (ILO/WHO, 1984). The combined effects of the shiftwork organization, age and lack of control at work were investigated by Loudoun et al. (2014) among Australian miners and their partners. Results showed that for older workers (50 years or more) low control over shift scheduling result in more sleep disturbances. Misalignment between shiftworkers and their partners work schedules contributed to dissatisfaction and imbalance of shiftworkers' lives. All these factors were associated with more sleep disturbances. The authors stressed the importance of integrating work and nonwork spheres particularly among older workers.

A balance between work and non-work hours is highly recommended. Working shifts can lead to less time available to perform physical activities during leisure time. Peplonska et al. (2014) studied a group of Polish nurses and midwives engaged in rotating night shiftwork. The aim of the study was to investigate the association between the shift schedule, occupational and non-occupational physical activities using the IPAQ questionnaire. The findings showed that physical activity was higher during night work. However, lower leisure time activity was associated with night work. 


\section{CONCLUDING REMARKS}

The collection of the 17 papers published in this Special Issue of Chronobiology International submitted after the International Symposium of Shiftwork and Working Time continues a good tradition that started in 2004. The papers derive from a variety of topics reflecting the comprehensiveness of the discipline Shiftwork and Working Time. Still there are controversies, particularly related to the effects of working time on chronic diseases, such as cancer, diabetes, hypertension, etc. We need to have better data on exposure to working time and working time patterns in epidemiological studies. The role of genetic polymorphisms in the etiology of cancer and its interaction with shiftwork begin to be revealed. The work context, as shown in some of the papers published herein, exerts influence in the outcomes, interacting with shiftwork schedules.

The current policies for working times including irregular work schedules, overtime and supplemental work from home during time off, can have detrimental health effects as showed by a large European survey. Several papers point to new avenues of research, such as those including the interaction between occupational and non-occupational variables. However, more intervention studies are required.

Important questions remain unanswered. The social and individual factors as determinants of workers' health, as well as health inequalities, still remain in large numbers of the global working population. Effects of poor work organization upon living and social conditions aggravate health and wellbeing.

Finally we wish to remember that we lost three important researchers that were closely related with our discipline: Prof. Israel Ashkenazi, Prof. Franz Halberg and Prof. Erhard Haus. All of them left a significant contribution in the area of Chronobiology. They will be remembered and missed by many of their friends and colleagues, as well as their legacy!

\section{ACKNOWLEDGEMENTS}

We would like to thank INFORMA Healthcare USA for their support to the Working Time Society in publishing this Special Issue, and Prof. Francesco Portaluppi, the Scientific Editor of Chronobiology International.

We also wish to acknowledge the editorial assistance of Amanda Aparecida Silva-Macaia, Elaine Cristina Marqueze, and Erica Lui Reinhardt.

A special thank you to all the reviewers of the submitted manuscripts:

John Fontenele Araújo, Federal University of Rio Grande do Norte, Brazil; Simon N. Archer, University of Surrey, United Kingdom; Josephine Arendt, University of Surrey, United Kingdom; Anna Arlinghaus, GAWO e.V., Germany; Kristan Aronson, Queen's University in Kingston, Canada; Domien Beersma,University of Groningen, The Netherlands; Massimo Bracci, Polytechnic University of Marche, Italy;Sarah Chellappa, Université de Liège, Belgium; Giovanni Costa, University of Milano, Italy; David Darwent, Central Queenland University, Australia; Dennis Dean, Harvard Medical School, USA; Lee Di Milia, Central Queensland University, Australia; Helen Driver, Queen's University, Canada; Anne Helene Garde, National Research Centre for the Working Environment, Denmark; Sandy Garden, Capital and Coast District Health Board, New Zeeland; Sally Ferguson, Central Queensland University, Australia; Adam Fletcher, Integrated Safety Support, Australia; Michelle Gibbs, University of Surrey, United Kingdom; Marijke Gordijn, Chrono@Work B.V., Netherlands; Rosane Harter Griep, Oswaldo Cruz Foundation, Brazil; Tarja Hakola, Finnish Institute of Occupational Health, Finland; Shelagh Hampton, University of Surrey, United Kingdom; Johnni Hansen, Danish Cancer Society Research Center, Denmark; Cynthia LaJambe, Penn State University, USA; Stavroula Leka, University of Nottingham, United Kingdom; Fernando Mazzilli Louzada, Parana Federal University, Brazil; Mikko Harma, Finnish Institute of Occupational Health, Finland; Marc Hébert, Université Laval, Canada; Ramon Hermida, University of Vigo, Spain; Ulf Holmback, University of Uppsala, Sweden; Anna Korompeli, National and Kapodistrian University of Athens, Greece; Jesper Kristiansen, The National Research Centre for the Working Environment, Denmark; Jonathan Leeder, English Institute of Sport, United Kingdom; Rebecca Loudoun, Griffith University, Australia; Arne Lowden, Stress Research Institute, Sweden; Charles Luenda, National Institute for Occupational Safety and Health, USA; Elaine Cristina Marqueze, Santos Catholic University, Brazil; Claudia Roberta de Castro Moreno, University of São Paulo, Brazil; Kristen Nabe-Nielsen, The National Research Centre for the Working Environment, Copenhagen, Denmark; Kyriaki Papantoniou, Centre for Research in Environmental Epidemiology (CREAL), Spain; Bhatti Parveen, Fred Hutchinson Cancer Research Center, USA; Kathryn Reid, Northwestern University, Chicago, USA; Alain Reinberg, Foundation A de Rothschild, France; Victoria L. Revell, University of Surrey, United Kingdom; Greg Roach, Central Queensland University, Australia; Melanie Rueger,VALKEE OY, Finland; Mikael Sallinen, Finnish Institute of Occupational Health, Finland; Nayantara Santhi, University of Surrey, United Kingdom; Philp Schluter, University of Canterbury, New Zealand; Michael Smolensky, University of Texas, USA; Yasushi Suwazono, University of Chiba, Japan; Philip Tucker, University of Swansea, United Kingdom; Sandra Vívolo, University of São Paulo, Brazil; Hans Van Dongen, Washington State University, USA; Eugene Waclawski, University of Alberta, Canada; 


\section{DECLARATION OF INTEREST}

We would like to acknowledge the sponsorship of institutions and professional associations which gave substantial support to the 21st International Symposium on Shiftwork and Working Time: the School of Public Health of the University of São Paulo, Oswaldo Cruz Foundation - FIOCRUZ, Rio de Janeiro; the Working Time Society; International Commission on Occupational Health (ICOH), Subcommittee of Shiftwork and Working Time; the Brazilian research agency $\mathrm{CNPq}$; the Brazilian Association of Sleep and Latin American Federation of Sleep Societies.

The authors report no conflicts of interest. The authors alone are responsible for the content and writing of the paper.

\section{REFERENCES}

Arlinghaus A, Nachreiner F. (2014). Health effects of supplemental work from home in the European Union. Chronobiol Int. 31:1100-7.

Artazcoz L, Cortez I, Escribá-Agüir V, et al. (2009). Understanding the relationship of long working hours with health status and health-related behaviours. J Epidemiol Community Health. 63: 521-7.

Balieiro LC, Rossato LT, Waterhouse J, et al. (2014). Nutritional status and eating habits of bus drivers during the day and night. Chronobiol Int. 31:1123-9.

Barnett A. (2006). Using recovery modalities between training sessions in elite athletes: Does it help? Sports Med. 36:781-96.

-Caruso CC, Bushnell T, Eggerth D, et al. (2006). Long working hours, safety, and health: Toward a National Research Agenda. Am J Ind Health. 49:930-42.

Caruso CC. (2006). Possible broad impacts of long work hours. Ind Health. 44:531-6.

Caruso CC. (2014). Negative impacts of shiftwork and long work hours. Rehabil Nurs. 39:16-25.

Costa G. (2010). Shift work and health: Current problems and preventive actions. Saf Health Work. 1:112-13.

- Costa G, Anelli MM, Castellini G, et al. (2014). Stress and sleep in nurses employed in " $3 \times 8$ " and " $2 \times 12$ " fast rotating shift schedules. Chronobiol Int. 31:1169-78.

Costa G, Di Milia L. (2008). Aging and shift work: A complex problem to face. Chronobiol Int. 25:165-81.

Dumont M, Paquet J. (2014). Progressive decrease of melatonin production over consecutive days of simulated night work. Chronobiol Int. 31:1231-8.

Harma M, Kecklund G. (2010). Shift work and health- how to proceed? Scand J Work Environ Health. 36:81-4.

-Haus EL, Smolensky MH. (2013). Shift work and cancer risk: Potential mechanistic roles of circadian disruption, light at night, and sleep deprivation. Sleep Med Rev. 17:273-84.

Ijaz S, Verbeek J, Seidler A, et al. (2013). Night-shift work and breast cancer - a systematic review and meta-analysis. Scan J Work Environ Health. 39:431-47.

ILO. (2005). Labour and social trends in Asia and the Pacific 2005. Geneva: ILO, Regional Office for Asia and the Pacific.

ILO. (2014). World of Work Report: 2014 Developing with jobs. Geneva: ILO, Research Department.

ILO/WHO. (1984). Recognition control of adverse psycho-social factors at work. Geneva: ILO/WHO, Committee on Occupation Health.

- Imai T, Kuwahara K, Nishihara A, et al. Japan Epidemiology Collaboration on Occupational Health Study Group. (2014).
Association of overtime work and hypertension in a Japanese working population: A cross-sectional study. Chronobiol Int. 31:1108-14.

-Jackson ML, Banks S, Belenky G. (2014). Investigation of the effectiveness of a split sleep schedule in sustaining sleep and maintaining performance. Chronobiol Int. 31:1218-30.

-Kantermann T, Duboutay F, Haubruge D, et al. (2014). The direction of shift-work rotation impacts metabolic risk independent of chronotype and social jetlag - An exploratory pilot study. Chronobiol Int. 31:1139-45.

Karhula K, Henelius A, Härmä M, et al. (2014). Job strain and vagal recovery during sleep in shift working health care professionals. Chronobiol Int. 31:1179-89.

Kawachi I. (2008). Globalization and workers' health. Chronobiol Int. 46:421-3.

Knauth P, Hornberger S. (2003). Preventive and compensatory measures for shift workers. Occup Med. 53:109-16.

Knauth P. (1998). Innovative worktime arrangements. Scan J Work Environ Health. 24:13-17.

Knutsson A, Kempe A. (2014). Shift work and diabetes - A systematic review. Chronobiol Int. 31:1146-51.

Kosmadopoulos A, Sargent C, Darwent D, et al. (2014). The effects of a split sleep-wake schedule on neurobehavioural performance and predictions of performance under conditions of forced desynchrony. Chronobiol Int. 31:1209-17.

Lee S, McCann D, Messenger JC. (2007). Working time around the World: Trends in working hours, laws and policies in a global comparative perspective. Geneva: ILO.

Lombardi DA, Jin K, Vetter C, et al. (2014). The impact of shift starting time on sleep duration, sleep quality, and alertness prior to injury in the People's Republic of China. Chronobiol Int. 31:1201-8.

Loudoun RJ, Muurlink O, Peetz D, Murray G. (2014). Does age affect the relationship between control at work and sleep disturbance for shift workers? Chronobiol Int. 31:1190-200.

Malcata RM, Hopkins WG. (2014). Variability of competitive performance of elite athletes: A systematic review. Sports Med. Aug 10. [Epub ahead of print].

Moreno C, Fischer FM, Rotenberg L. (2013). The 24/7 society: From chronobiology to practical life. Sleep Sci. 6:s5-s80.

Moreno C, Lowden A. (2014). Workplace interventions: A challenge for promoting long-term health among shift workers. Scand J Work Environ Health. 40: 539-41.

-Mota MC, Waterhouse J, De-Souza DA, et al. (2014). Sleep pattern is associated with adipokine levels and nutritional markers in resident physicians. Chronobiol Int. 31:1130-8.

- Nakanishi N, Yoshida H, Nagano K, et al. (2001). Long working hours and risk for hypertension in Japanese male white collar workers. J Epidemiol Community Health. 55:316-22.

- Peplonska B, Bukowska A, Sobala W. (2014). Rotating night shift work and physical activity of nurses and midwives in the cross-sectional study in Łódź, Poland. Chronobiol Int. 31:1152-9.

Quinlan M, Mayhew C, Bohle P. (2001). The global expansion of precarious employment, work disorganization, and consequences for occupational health: Placing the debate in a comparative historical context. Int J Health Serv. 31: 721-44.

Rabstein S, Harth V, Justenhoven C, et al. on behalf of the GENICA Consortium. (2014). Polymorphisms in circadian genes, night work and breast cancer: Results from the GENICA study. Chronobiol Int. 31:1115-22.

- Rea MS, Figueiro MG. (2014). Quantifying light-dependent circadian disruption in humans and animal models. Chronobiol Int 31:1239-46.

Santana VS. (2012). Employment, work conditions and health. Salud Colectiva. 8:101-6. 
Sargent C, Lastella M, Halson SL, Roach GD. (2014). The impact of training schedules on the sleep and fatigue of elite athletes. Chronobiol Int. 31:1160-8.

Szosland D. (2010). Shift work and metabolic syndrome, diabetes mellitus and ischaemic heart disease. Int J Occup Med Environ Health. 8:1-5.

Viswanathan AN, Schernhammer ES. (2009). Circulating melatonin and the risk of breast and endometrial cancer in women. Cancer Lett. 281:1-7.
-Wada K, Katoh N, Aratake Y, et al. (2006). Effects of overtime work on blood pressure and body mass index in Japanese male workers. Occup Med. 56:578-80.

World Health Organization/International Agency for Research on Cancer (IARC). (2007). IARC monographs on the evaluation of carcinogenic risks to humans. Volume 98. Painting, firefighting and shiftwork. Lyon: WHO Press.

-Yang H, Schnall PL, Jaurequi M, et al. (2006). Work hours and selfreported hypertension among working people in California. Hypertension. 48:744-50. 